\title{
NEGOCIACIÓN COLECTIVA PÚBLICA $Y$ RESPONSABILIDAD ESTATAL
}

Natalia Veloso Giribaldi*

\begin{abstract}
RESUMEN: La negociación colectiva en el sector público presenta ciertas particularidades derivadas del carácter estatal de una de las partes. En efecto, el Estado se encuentra acotado en su capacidad de negociación por el marco presupuestal que le otorgan las normas, lo cual marcará la tónica de la negociación y ejecución de los acuerdos. En este contexto, es necesario preguntarse si el Estado incurre en responsabilidad cuando por dichas particularidades incumple con los convenios alcanzados y asimismo, si es susceptible de incurrir en responsabilidad precontractual por la conducta que adopte en el marco de la negociación.
\end{abstract}

PALABRAS CLAVES: Negociación colectiva. Sector público. Convenios colectivos. Responsabilidad estatal. Responsabilidad pre contractual

\begin{abstract}
Collective bargaining in the public sector has certain particularities due to the fact that one of the parties is the State. In effect, the State is limited in its bargaining capacity by virtue of the budget approved by the rules, which determinesthe margin for negotiation and execution of agreements of the State. In this context, it must be questioned whether the State will be responsible, when, for such particularities, agreements reached. Additionally, this paper will analyze if the State could be subject to pre-contractual liability for any behavior adopted within the framework of the negotiation.
\end{abstract}

KEY WORDS: Collective bargaining. Public sector. Collective agreements. State responsibility. Pre-contractual liability.

\footnotetext{
* Doctora en Derecho por la Universidad de Montevideo (2005), Máster en Derecho Administrativo Económico (2011), Profesor Adscripto de Derecho Administrativo I y II en la Universidad de Montevideo (2006-2014), Profesor Agregado de Derecho Administrativo I y II en la Universidad de Montevideo (2015actualidad). Profesora de Derecho Público en el Posgrado de Gestión Financiera en Instituciones Públicas de la Universidad de la República (2018 a la actualidad).natalia.veloso@delpiazzo.com
} 


\section{PLANTEO DEL TEMA}

En nuestro país, los primeros antecedentes de la negociación colectiva en el sector público se remontan al período de elaboración de la Ley de Presupuesto $\mathrm{N}^{\circ} 13.640$ de 26 de diciembre de $1967^{1}$. No obstante, con el dictado de la Ley $\mathrm{N}^{\circ} 18.508$ de 26 de junio de 2009, se le confirió un marco regulatorio que contempla ciertas particularidades que se apartan del régimen de la negociación colectiva en el sector privado.

En efecto, dichas particularidades guardan relación directa con el carácter estatal de una de las partes, que, como tal, se rige por un régimen de Derecho público. Es que a diferencia de lo que sucede en la negociación colectiva en el sector privado, las organizaciones de funcionarios no cuentan con "estados contables", ni con "proyecciones de flujos de fondos" que les permitan prever a ciencia cierta cuál será la disponibilidad económica real con la que cuenta el organismo estatal para hacer frente a reivindicaciones sindicales. Por el contrario, toda la dinámica financiera estatal se estructura en base a un régimen constitucional presupuestario, conforme con el cual, en algunos casos, los órganos intervinientes en la negociación ni siquiera aprueban su propio presupuesto.

En este sentido, se ha señalado que: "En un Estado de Derecho, para tomar sus decisiones se encuentra sometido a normas constitucionales y legales, así como al contralor de ciertos órganos. Por ejemplo, las remuneraciones de los funcionarios suponen un coste económico que debe reflejarse en los presupuestos públicos, cuya aprobación compete a órganos como el Parlamento o las Juntas Departamentales. Estos órganos no necesariamente son los empleadores de los funcionarios públicos y sus decisiones tienen que tener en cuenta la situación económica del país y el interés general. Por esta razón, las personas que negocian en la Administración pública se ven sometidas a las directivas o al control de un órgano exterior como el MEF, o una comisión interministerial"2 .

Dichas particularidades, determinan dificultades en la propia negociación y ejecución de los acuerdos arribados en la negociación colectiva del sector público, por ser otros los organismos o dependencias estatales que confieren o no los créditos presupuestales o tienen atribuida la competencia para dictar los actos jurídicos necesarios para poder cumplir con los compromisos asumidos por la delegación estatal.

En esas oportunidades, se plantea la interrogante jurídica acerca de si los entes estatales incurren o no en responsabilidad civil cuando por estas causas, no pueden cumplir un compromiso arribado en el marco de la negociación colectiva pública. Asimismo, en caso de que efectivamente se configurara responsabilidad, cabría además preguntarse si la misma sería de índole contractual o extracontractual e inclusive, si existe la posibilidad de que el Estado incurra en responsabilidad precontractual por no acudir suficientemente instruido o con poderes suficientes o por no brindar toda la información necesaria para que la negociación llegue a buen puerto. Al análisis de dichas interrogantes se dedicarán los siguientes apartados.

${ }^{1}$ PANIZZA DOLABDJIAN, Carolina - "La negociación colectiva en el sector público" en XXVI Jornadas de Derecho del Trabajo y la Seguridad Social, F.C.U., Montevideo, 2015, pág. 225 y ss. Ver también: RACCIATTI, Octavio, GARMENDIA, Mario y GOLDFLUS, Sandra - "Relaciones industriales, incluyendo disputas colectivas en el sector público." en Revista de Derecho Laboral, Tomo XLIII, № 199, JulioSetiembre 2000, Montevideo, 2000, pág. 577.

${ }^{2}$ BAJAC, Laura - "La negociación colectiva en el sector público" en Revista Transformación, Estado y Democracia $\mathrm{N}^{\circ} 35$, pág. 37 y 38. 


\section{LA NEGOCIACIÓN COLECTIVA EN EL SECTOR PÚBLICO}

\subsection{Definición y sujetos alcanzados}

La Ley $\mathrm{N}^{\circ} 18.508$ en su art. $4^{\circ}$ define la negociación colectiva en el sector público como aquella que tiene lugar entre: a) "uno o varios organismos públicos, o una o varias organizaciones que los representen"; y, por otra parte; b) "una o varias organizaciones representativas de funcionarios públicos".

En este sentido, cuando la ley refiere a "organismos públicos" entendemos que en realidad está haciendo referencia a reparticiones estatales. En efecto, el carácter "público" de una institución refiere al Derecho por el cual se rige, siendo pública si se rige por Derecho público y privada si se rige por Derecho privado ${ }^{3}$. Por el contrario, la estatalidad refiere a su pertenencia o no a la organización estatal ${ }^{4} \mathrm{y}$, en definitiva, a si se le aplica o no el régimen de la estatalidad ${ }^{5}$.

En este caso, entendemos que cuando la ley refiere a "organismos públicos", está refiriendo a organismos estatales, quedando de esta forma excluidas de su ámbito de aplicación aquellas organizaciones como las personas públicas no estatales, que si bien son públicas (porque se rigen por Derecho público) no son estatales porque no pertenecen a la organización estatal y por no aplicárseles, por tanto, el régimen de la estatalidad.

Avalan esta conclusión varios argumentos. En primer lugar, esta es la única explicación que resulta compatible con que la otra parte en la negociación colectiva sean "una o varias organizaciones representativas de funcionarios públicos". En efecto, los trabajadores de las entidades paraestatales no son funcionarios públicos ${ }^{6}$, sino que son trabajadores regidos por el Derecho laboral común, por lo que evidentemente, este tipo de organismos no podría negociar con "organizaciones de funcionarios públicos", tal como lo prevé la ley.

En segundo lugar, cuando la ley regula en su art. $8^{\circ}$ el ámbito de aplicación de la norma, establece que: "Quedan comprendidos en el ámbito de aplicación de esta ley el Poder Ejecutivo, el Poder Legislativo, el Poder Judicial, el Tribunal de lo Contencioso Administrativo, el Tribunal de Cuentas, la Corte Electoral, los entes autónomos, servicios descentralizados y los Gobiernos Departamentales (Intendencias Municipales, Juntas Departamentales y Juntas Locales Autónomas Electivas)".

Tal como puede apreciarse, la ley hace una mención expresa a todos los organismos integrantes del Estado en sentido estricto (los tres Poderes de Gobierno y los tres órganos de creación constitucional) y a las entidades integrantes del Estado en sentido amplio ${ }^{7}$ (Entes Autónomos, Servicios Descentralizados y Gobiernos Departamentales). Esto es,

${ }^{3}$ SAYAGUÉS LASO, Enrique - "Criterio de distinción entre las personas jurídicas públicas y privadas", Revista de Derecho Público y Privado, Año VII, N 83, pág. 259 y ss.

${ }^{4}$ DELPIAZZO, Carlos E. - "Derecho Administrativo Especial”, AMF, Montevideo, 2015, Volumen 1, Tercera Edición Ampliada y Actualizada, pág. 199.

${ }^{5}$ CAJARVILLE, Juan Pablo - "Sobre Derecho Administrativo", F.C.U., Montevideo, 2009, Tomo I, pág. 719 y ss. y VELOSO, Natalia - "Sociedades de Economía Mixta”, A.M.F., Montevideo, 2012 , pág. 56.

${ }^{6}$ CAGNONI, José Aníbal - "Evolución del Régimen Jurídico de las personas públicas no estatales" en Revista de Derecho Público, F.C.U., Montevideo, 1992, º 1, pág. 27 y ss. y DELPIAZZO, Carlos - "Derecho Administrativo Especial”, cit., Volumen 1, Tercera Edición Ampliada y Actualizada, pág. 201. 
reseña todas las entidades estatales, sin nombrar en ningún caso a un organismo paraestatal.

En consecuencia, entendemos que cuando la ley define en su art. $4^{\circ}$ la negociación colectiva como aquella que se da entre una o varias organizaciones de funcionarios públicos y uno o varios “organismos públicos", se está refiriendo en realidad a "organismos estatales", esto es, sujetos de Derecho, órganos o sistemas orgánicos que pertenezcan a la estructura estatal.

Por otra parte, la ley exige que también exista "una o varias organizaciones representativas de funcionarios públicos". Al respecto, entendemos que debe aplicarse el concepto legal y doctrinario de funcionario público, conforme con el cual se ha dado una interpretación amplia a dicho concepto.

En efecto, el art. $3^{\circ}$ de la Ley $\mathrm{N}^{\circ} 19.121$ de 20 de agosto de 2013 establece que "es funcionario público todo individuo que, incorporado mediante un procedimiento legal, ejerce funciones públicas... bajo una relación de subordinación y al servicio del interés general" (inc. $1^{\circ}$ ). Asimismo, el art. 175 del Código Penal dispone que: "A los efectos de este Código, se reputan funcionarios a todos los que ejercen o desempeñan una función retribuida o gratuita, permanente o temporaria, de carácter administrativo, legislativo o judicial en el Estado, en el Municipio o en cualquier ente público"8.

En consonancia con ello, la doctrina ha entendido que: "parece claro que la noción de funcionario público aceptada en nuestro derecho es amplísima, ingresando en ella, todos aquellos individuos que ejercen función pública, incorporados por procedimiento legal, sea en el Estado Persona Pública Mayor, en los Gobiernos Departamentales, en los Entes Autónomos o en los Servicios Descentralizados, sean o no de carrera, retribuidos u honorarios, presupuestados o contratados, civiles, policiales, militares, diplomáticos, etc." $"$

Quiere decir, que no solo los funcionarios presupuestados podrán ser sujetos de negociación colectiva pública, sino también los funcionarios contratados y todos aquellos, que ingresen dentro del concepto legal y doctrinario de funcionario público.

Por otra parte, en cuanto a la representatividad de las diferentes organizaciones de los trabajadores, debe tenerse presente que la ley refiere a "una o varias organizaciones representativas de funcionarios públicos" sin disponer ningún tipo de referencia a cómo podría resolverse la existencia de un conflicto entre dos organizaciones que se irroguen la representación de un determinado colectivo de trabajadores. En este caso, dependiendo del nivel de negociación de que se trate, corresponderá al Ministerio de Trabajo y Seguridad Social, definir qué organización representa a los funcionarios públicos según la rama o el sector objeto de la negociación.

7 DELPIAZZO, Carlos E. - "Derecho Administrativo Especial”, cit., Volumen 1, Tercera Edición Actualizada y Ampliada, pág. 37.

${ }^{8}$ Dicho concepto aparece recogido además en el art. $2^{\circ}$ de la llamada ley anticorrupción $\mathrm{N}^{\circ} 17.060$ de 23 de diciembre de 1998.

9 CORREA FREITAS, Rubén y VÁZQUEZ, Cristina en "Manual sobre la función pública", F.C.U., Montevideo, 1998, pág. 35 y 36. Ver también: SAYAGUÉS LASO, Enrique - "Tratado de Derecho Administrativo", Montevideo, 1974, Tomo I, pág. 263; PRAT, Julio - "Derecho Administrativo", Montevideo, 1978, Tomo III, volumen I, pág. 29. 


\subsection{Objeto}

En cuanto al objeto de la negociación colectiva en el sector público, el art. $4^{\circ}$ de la Ley establece que la misma propenderá a alcanzar acuerdos que regulen los siguientes aspectos: a) las condiciones de trabajo, salud e higiene laboral; b) el diseño y planificación de la capacitación y formación profesional de los empleados en la función pública; c) la estructura de la carrera funcional; d) el sistema de reforma de la gestión del Estado, criterios de eficiencia, eficacia, calidad y profesionalización; e) las relaciones entre empleadores y funcionarios; y f) las relaciones entre uno o varios organismos públicos y la o las organizaciones de funcionarios públicos correspondientes y todo aquello que las partes acuerden en la agenda de la negociación.

Tal como puede advertirse, dentro del concepto de "condiciones de trabajo" no solo pueden negociarse condiciones de remuneración ${ }^{10}$, sino también otro tipo de condiciones como aquellas relativas a la naturaleza jurídica de los funcionarios (ej. solicitud de presupuestación de funcionarios contratados) o inclusive, las condiciones de capacitación y formación o la estructura misma de la carrera funcional para un determinado sector de actividad.

En efecto, el alcance del objeto de la negociación ha sido deliberadamente abierto por la Ley, que permite incluso incluir cualquier tema que las partes acuerden como materia de negociación $^{11}$.

Sin perjuicio de ello, se comparte lo señalado en cuanto a que el ajuste o no a Derecho del ejercicio de la potestad disciplinaria, no puede ser objeto de negociación colectiva. En este sentido, se ha señalado que: "el ejercicio de la potestad disciplinaria por parte de la Administración, que es irrenunciable de acuerdo al artículo 70 de la Ley $\mathrm{N}^{\circ} 19.121$ de 20 de agosto de 2013 (que regula el Estatuto del Funcionario Público de la Administración Central), no puede ser, bajo ningún concepto, materia u objeto de negociación colectiva. En las mesas de negociación entre la Administración y los funcionarios, no puede ponerse como un punto del Orden del Día "levantamiento de sanciones a funcionarios”, esto es, y más claro: la Administración no puede negociar las sanciones que haya impuesto a sus funcionarios en los ámbitos de negociación colectiva"12 .

Entendemos que ello es así no solo porque la potestad disciplinaria es irrenunciable de principio, sino porque, además, el órgano con competencia exclusiva para revisar el ajuste o no a derecho de los actos administrativos que imponen sanciones es el Tribunal de lo Contencioso Administrativo (art. 309). Asimismo, la potestad de revisar sus propios actos (ya sea de oficio o a partir de la interposición de los correspondientes recursos administrativos) es exclusiva de la Administración y se rige por normas especiales propias de derecho

${ }^{10} \mathrm{Al}$ respecto se ha señalado que: "Si bien no se menciona al salario en forma expresa, se ha entendido que el mismo queda comprendido dentro de la expresión "condiciones de trabajo": Así: PANIZZA DOLABDJIAN, Carolina - "La negociación colectiva en el sector público" en XXVI Jornadas de Derecho del Trabajo y la Seguridad Social, cit., pág. 225 y ss.

${ }^{11}$ DURAN, Beatriz y SANTESTEVAN, Ana - "Ley No 18.508 en el sector público" en "Cuarenta Estudios sobre la Nueva Legislación Laboral Uruguaya”, F.C.U., Montevideo, 2010, pág. 74 y ss.

12 SCHIAVI, Pablo - “¿Convenios colectivos de la Administración son fuente de derecho administrativo? En Revista de Derecho Administrativo Económico, Pontificia Universidad Católica de Chile, Número 29, Año. 2019. 
público cuyo ejercicio de ninguna forma puede estar compartido con una o varias organizaciones de funcionarios.

\subsection{Obligaciones y Derechos}

La Ley $\mathrm{N}^{\circ} 18.508$ establece obligaciones y derechos de fundamental importancia que deben regir durante la negociación colectiva pública. Dichas obligaciones y derechos, cobran especial importancia al analizarse la responsabilidad del Estado en caso de incumplimiento de los convenios colectivos del sector público.

\subsubsection{Obligación de negociar de buena fe}

El art. $5^{\circ}$ de la Ley establece que las partes tienen la obligación de negociar de buena $\mathrm{fe}^{13}$. Al respecto, nuestra doctrina ha entendido que "el principio o deber general de actuar de buena fe tiene la función de colmar las inevitables lagunas del sistema legal; la ley, por cuidada y detallista que sea, no puede prever todas las situaciones posibles mediante normas concretas, ni todos los abusos que las partes puedan cometer, una en perjuicio de otra"14. En el mismo sentido, se ha señalado que la buena fe "cumple una función que la coloca orgánicamente en el sistema de fuentes (primarias según entiende Bianca) de interpretación del contrato, que junto a la equidad y la natura contractus determina reglas, efectos y obligaciones no enunciados en la convención, pero coherentes con el programa negocial establecido"15.

Sin perjuicio de ello, el art. $5^{\circ}$ enumera una serie de derechos y obligaciones de las partes que emanarían justamente de la obligación de negociar de buena fe. Si bien se entiende que las mismas no son taxativas, resulta de especial interés analizarlas por la implicancia directa que tienen cuando se negocia con el Estado.

En primer lugar, se establece el deber de concurrir a las negociaciones y a las audiencias citadas en debida forma (art. 5 lit. A); la realización entre las partes de las reuniones que sean necesarias, en los lugares y con la frecuencia y periodicidad que sean adecuadas (art. 5 lit. B) y la realización de los esfuerzos conducentes a lograr acuerdos que tengan en cuenta las diversas circunstancias del caso (art. 5 lit. E).

Estas obligaciones y deberes, resultan elementales para que efectivamente se pueda generar un ámbito propicio para la negociación. En efecto, el deber de asistir y de acudir cuantas veces sea necesario para llevar adelante la negociación, resulta un elemento básico e indispensable para que se produzca la misma. No obstante, no basta con asistir a los ámbitos de negociación para no violentar la obligación de negociar de buena fe, sino que la

${ }^{13}$ Ver: LABORDE GOÑI, Marcelo - "El principio de buena fe como rector del Ejercicio de la Función Pública” en Revista de Derecho Público, F.C.U., 2016, Año 25, Número 50, diciembre de 2016 , pág. 67 y GAMARRA, Jorge - "Vigencia actual del principio de buena fe" en Anuario de Derecho Civil Uruguayo, F.C.U., Montevideo, 1977, Tomo VII, pág. 92

${ }^{14}$ LÓPEZ MESA, Marcelo J. y ROGEL VIDE, Carlos - "La doctrina de los actos propios" editorial Reus y BdeF, año 2005, pág. 64 .

${ }^{15}$ BLENGIO, Juan - "El principio de equilibrio con especial referencia a su incidencia en la ecuación contractual en la emergencia económica. Primera Parte” - F.C.U., Montevideo, 2005, en ADCU, Tomo XXXV, pág. 590). 
ley exige además que exista una verdadera voluntad de alcanzar acuerdos y exige para ello, la realización de los esfuerzos necesarios tendientes a alcanzarlos.

En este sentido, si bien las partes están obligadas a negociar, obviamente no están obligadas a alcanzar acuerdos. Al respecto, es claro el inciso final del art. $4^{\circ}$ cuando dispone que: "Las partes están obligadas a negociar, lo que no impone la obligación de concretar acuerdos". No obstante, si resultara probado que la presencia de alguna de las partes es meramente nominal y que en realidad no existe, intención alguna de negociar y de llegar a un acuerdo, entonces dicha parte estaría violentando su obligación de negociar de buena fe, lo cual sin dudas aparejaría la correspondiente responsabilidad de su parte. Es a raíz de ello que acertadamente se ha señalado que: "La no asistencia a las reuniones convocadas o su dilatoria, la no proporción de informaciones necesarias o su entrega tardía son indicios que demuestran la inexistencia de buena fe en la negociación"16 .

En segundo lugar, se establece la obligación de designar negociadores con idoneidad y representatividad suficientes para la discusión del tema que se trata (art. 5 lit. C).

Este punto, cobra especial relevancia teniendo en cuenta que no cualquier funcionario designado por el Estado para representarlo en el Consejo de Salarios del Sector Público cuenta con la representatividad suficiente como para vincular al Estado con sus decisiones. En efecto, puede suceder que el funcionario representante del organismo estatal no pueda acceder a convenir sobre una determinada materia, para la cual no tiene competencia o representación suficiente.

De no estar especialmente reguladas por la Ley, dichas circunstancias permitirían fácilmente al organismo estatal evadirse de su deber de negociar, ya que bastaría con invocar la ausencia de representatividad suficiente o la necesidad de consultar con otros órganos, para truncar en los hechos cualquier tipo de negociación.

Máxime, si se tiene en cuenta que, en muchos casos, la repartición estatal que acude no tiene autonomía presupuestal, y, por ende, los recursos con los que cuenta, ni siquiera son aprobados por dicho organismo, sino que dependen de la voluntad de otro órgano o sujeto jurídico estatal.

Es por ello, que, previniendo dicha situación, la Ley prevé que quienes acudan a negociar, deben tener la idoneidad y la "representatividad suficiente" para poder vincular al Estado mediante la negociación colectiva. De lo contrario, la negociación colectiva en el sector público carecería de sentido, salvo con aquellos organismos que, conforme a nuestro ordenamiento, dictaminan su propio presupuesto y son capaces de comprometer futuros gastos.

Es por ello que los negociadores designados deben tener representatividad suficiente como para comprometer la responsabilidad del Estado en el sentido pactado, ya que ella es la única interpretación compatible con negociar de buena fe. Ello es así, ya que quien negociara y alcanzara acuerdos colectivos a sabiendas de que no tiene certeza de si puede cumplir con lo acordado, no puede estar sino de mala fe y con ello, violar la obligación de negociar de buena fe establecida por la Ley.

${ }^{16}$ PANIZZA DOLABDJIAN, Carolina - "La negociación colectiva en el sector público” en XXVI Jornadas de Derecho del Trabajo y la Seguridad Social, cit., pág. 225 y ss. 
Asimismo, si bien la representatividad de las organizaciones de trabajadores no plantea las mismas dificultades que la representatividad del Estado, lo mismo vale decir respecto de estas organizaciones de funcionarios públicos, cuyos negociadores deben ser idóneos para la negociación y tener representación suficiente como para vincular a los funcionarios.

En tercer lugar, se establece el deber de intercambiar la información necesaria a los fines del examen de las cuestiones en debate (art. 5 lit. D). Al respecto, no puede perderse de vista que, en el sector público, la organización de funcionarios no cuenta con los balances del empleador o con las proyecciones del mismo para el próximo ejercicio. Por el contrario, el sistema de contabilidad estatal y las previsiones de créditos presupuestales presentan una gran complejidad, que, dependiendo del organismo estatal, puede dificultar inclusive su comprensión y análisis. Es por ello, que este deber cobra especial relevancia, debiéndose intercambiar toda aquella información que sea necesaria para poder llevar adelante la negociación colectiva, intentando además presentarla en forma comprensible para la otra parte.

Asimismo, en caso de que dicha información no sea suministrada por la entidad estatal correspondiente, no solo se comprometerá la responsabilidad de la misma, sino que, además, podrá entablarse la correspondiente solicitud de acceso a la información pública en los términos establecidos por la Ley de Acceso a la Información Pública $\mathrm{N}^{\circ} 18.381$ de 17 de octubre de 2008 .

\subsubsection{Derecho a la información}

El art. $6^{\circ}$ de la Ley establece el derecho a la información por el cual se dispone que las partes tienen la obligación de proporcionar, en forma previa y recíproca, la información necesaria que permita negociar con conocimiento de causa. Concretamente, se establece que: "El Estado, a solicitud de las organizaciones representativas de los trabajadores del sector público, deberá suministrar a las mismas toda la información disponible referente a: a) los avances de los proyectos de Presupuesto y Rendición de Cuentas y Balance de Ejecución Presupuestal; b) la situación económica de los organismos y unidades ejecutoras y la situación social de los funcionarios; c) los cambios tecnológicos y reestructuras funcionales a realizar; d) los planes de formación y capacitación para los trabajadores y e) posibles cambios en las condiciones de trabajo, seguridad, salud e higiene laboral".

$\mathrm{Al}$ respecto de esta obligación se ha señalado que: "El cumplimiento de este deber ha tenido algunas dificultades en la práctica, en el sentido de que la dinámica de elaboración de las normas presupuestales, impiden en algunos casos presentar los proyectos con la antelación debida. Este hecho, llevó a que, en el año 2011, la Confederación de Organizaciones de Funcionarios del Estado (COFE) presentara una Queja ante el Comité de Libertad Sindical por considerar que el Poder Ejecutivo envió al Parlamento el proyecto de Presupuesto 2010-2014, sin haber negociado las condiciones de trabajo con la organización sindical. En este caso, el Comité aceptó las explicaciones brindadas por el Gobierno Uruguayo y señaló que "no puede concluir que no haya habido negociaciones verdaderas". No obstante, recomendó que las normas presupuestales que afecten los intereses de los interlocutores sociales sean puestas en conocimiento de las partes en la negociación ${ }^{17}$ ".

${ }^{17}$ PANIZZA DOLABDJIAN, Carolina - "La negociación colectiva en el sector público" en XXVI Jornadas de Derecho del Trabajo y la Seguridad Social, cit., pág. 225 y ss. 
Sin perjuicio de ello, entendemos que el organismo estatal tiene la obligación de hacer sus máximos esfuerzos para presentar los proyectos y los avances con la antelación debida y de forma comprensible y que, si no lo hace, incumple con su deber incurriendo en la correspondiente responsabilidad frente a la o las organizaciones de funcionarios respectivas.

\section{4. Órgano de aplicación}

El art. 9 de la Ley $N^{\circ} 18.508$ establece que el Ministerio de Trabajo y Seguridad Social "será el organismo encargado de velar por la aplicación de la presente ley” y que "En tal carácter, coordinará, facilitará y promoverá las relaciones laborales y la negociación colectiva en el sector público. Cumplirá funciones de conciliación y de mediación y dispondrá de las medidas adecuadas para asegurar el cumplimiento de los acuerdos".

Desde el punto de vista orgánico, no puede perderse de vista que-a diferencia de lo que sucede en el ámbito privado- en el caso de la negociación colectiva pública el Ministerio de Trabajo y Seguridad Social no es un tercero. Por el contrario, dicho Ministerio integra el Poder Ejecutivo y como tal, tiene participación directa en la confección del Presupuesto Nacional y también interviene en los presupuestos de los organismos del arts. 220 y 221 de la Constitución.

Sin perjuicio de su ubicación orgánica, dada la especialidad del mismo en materia de negociación colectiva, la Ley lo erigió como órgano de conciliación, mediación y aplicación de la ley, aspecto para el cual deberá intentar actuar con la mayor independencia técnica posible.

\subsection{Niveles de negociación}

En el caso de la negociación colectiva en el sector público existen diferencias importantes dependiendo de la Administración pública con la cual se tenga que negociar.

\subsubsection{Negociación con el Poder Ejecutivo y Entes Autónomos y Servicios Descentralizados del dominio comercial e industrial del Estado}

En el caso de negociación con dichas reparticiones estatales, la Ley establece tres niveles distintos de negociación: a) el General o de nivel superior, a través del Consejo Superior de Negociación Colectiva del Sector Público; b) el Sectorial o por rama, a través de las mesas de negociación establecidas en función de las particularidades o autonomías y c) por inciso u organismo a través de mesas de negociación entre las organizaciones sindicales representativas de base y los respectivos organismos.

El nivel general o de nivel superior, se llevará adelante a través del Consejo Superior de Negociación Colectiva del Sector Público que actuará por consenso y estará integrado por: i) dos representantes del Ministerio de Trabajo y Seguridad Social (uno de los cuales presidirá el Consejo), ii) dos representantes del Ministerio de Economía y Finanzas, iii) dos representantes de la Oficina de Planeamiento y Presupuesto, iv) dos representantes de la Oficina Nacional del Servicio Civil; y v) ocho representantes de las organizaciones sindicales más representativas de funcionarios públicos de mayor grado a nivel nacional. 
El nivel sectorial o por rama, se llevará adelante a través de las mesas de negociación establecidas en función de las particularidades o autonomía que se integrará con: i) dos representantes de la Oficina de Planeamiento y Presupuesto, ii) dos representantes del Ministerio de Economía y Finanzas, iii)dos representantes de la Oficina Nacional del Servicio Civil, dos representantes del Ministerio de Trabajo y Seguridad Social; y iv) ocho delegados designados por la organización representativa de los funcionarios públicos del respectivo sector o rama. Asimismo, en el caso de los entes autónomos y servicios descentralizados, el ámbito de negociación podrá integrarse, además, con representantes de las referidas instituciones.

El nivel por inciso u organismo, a través de las mesas de negociación que estarán compuestas por: i) las organizaciones sindicales representativas de base; $y$ ii) las autoridades de los respectivos organismos.

\subsubsection{Negociación con el Poder Judicial, Poder Legislativo, el Tribunal de lo Contencioso Administrativo, la Corte Electoral, el Tribunal de Cuentas, los entes autónomos de la Enseñanza Pública, y los Gobiernos Departamentales (Intendencias Municipales, Juntas Departamentales y Juntas Locales Autónomas Electivas).}

Cuando se trata de estos organismos, la negociación se hará a través de mesas de negociación que se integrarán de la siguiente forma:i) dos representantes del organismo correspondiente; ii) tres delegados designados por la organización representativa de los funcionarios; iii) un representante del Ministerio de Trabajo y Seguridad Social que actuará como coordinador o facilitador; y iv) asimismo, podrán participar, como asesores, delegados de la Oficina de Planeamiento y Presupuesto, de la Oficina Nacional del Servicio Civil y del Ministerio de Economía y Finanzas. Por su parte, la Ley establece que cada mesa de negociación definirá los ámbitos y niveles de funcionamiento según las necesidades y particularidades de cada organismo.

Al respecto, especial tratamiento merecen los llamados Entes Autónomos y Servicios Descentralizados "sociales" ${ }^{18}$, que no son ni del dominio comercial e industrial del Estado, ni tampoco son Entes Autónomos de enseñanza. Tal como puede apreciarse, dichos entes no están incluidos en el art. 14 de la Ley, ni tampoco lo están en el art. 10 que refiere únicamente al Poder Ejecutivo y a los Entes Autónomos y Servicios Descentralizados del dominio comercial e industrial del Estado.

Sin embargo, cuando en el art. 8 la Ley define su ámbito de aplicación, claramente incluye a dichos entes y servicios "sociales" 19 , ya que no distingue entre las diferentes categorías de entidades descentralizadas sino que establece que "quedan comprendidos en el ámbito de aplicación de esta Ley el Poder Ejecutivo, el Poder Legislativo, el Poder Judicial, el Tribunal de lo Contencioso Administrativo, el Tribunal de Cuentas, la Corte Electoral,

18 DELPIAZZO, Carlos E. - "Derecho Administrativo Especial”, cit., Volumen 1, Tercera Edición Actualizada y Ampliada, pág. 131

${ }^{19}$ En esta categoría se encuentran la Administración de Servicios de Salud del Estado, el Instituto Nacional de Colonización, el Instituto Nacional de Meteorología, el Instituto del Niño y Adolescente del Uruguay, y el Sistema Público de Radio y Televisión Nacional. 
los entes autónomos, servicios descentralizados y los Gobiernos Departamentales (Intendencias Municipales, Juntas Departamentales y Juntas Locales Autónomas Electivas)”.

Por lo tanto, no hay duda que los mismos quedan comprendidos en el ámbito de la Ley de negociación colectiva, sin perjuicio de lo cual, lo que no queda claro es si dichos entes autónomos y servicios descentralizados denominados sociales deben negociar bajo el régimen del primer (art. 10) o segundo grupo de organizaciones estatales (art. 14).

$\mathrm{Al}$ respecto, entendemos que, conceptualmente, los Entes Autónomos y Servicios Descentralizados denominados sociales encuadran jurídicamente mejor dentro del segundo grupo de entidades (art. 14) que dentro de las primeras (art. 10). Ello en tanto los demás organismos que comparten régimen presupuestal con este tipo de entidades descentralizadas (art. 220 de la Constitución) se encuentran todos en el segundo grupo de organismos (a diferencia de los del dominio industrial y comercial del Estado, que se rigen por el art. 221 dela Constitución). Sin embargo, en la práctica, dichos entes descentralizados denominados "sociales" han funcionado en el primero de los grupos ${ }^{20}{ }^{21}$.

\section{PARTICULARIDADES EN LA IMPLEMENTACIÓN DE ACUERDOS EN EL SECTOR PÚBLICO}

La implementación de los acuerdos a los cuales se arriba en sede de negociación colectiva pública, reviste ciertas dificultades en tanto "no siempre se recogen en convenios colectivos, y muchas veces cuando sí se realizan, necesitan de un decreto, resolución o ley. Este aspecto de la negociación, se relaciona con el tema de las fuentes del Derecho y su funcionamiento en el Derecho del Trabajo y en el Derecho Administrativo. Cuestión que, en esta etapa de desarrollo de la negociación colectiva en el sector público, no está resuelta. Así, el acuerdo al que se arribe puede ser eficaz, pero estar condicionado su instrumentación por un acto de gobierno. Por otra parte, el acuerdo puede estar sujeto a la ratificación o aprobación por un tercero. Por ejemplo, el Presupuesto, que puede recoger acuerdos entre los funcionarios públicos y la Administración Central, debe ser aprobado por el Poder Legislativo, que no fue parte en la negociación" ${ }^{2}$.

Atendiendo a esta realidad, nuestra doctrina ${ }^{23}$ ha distinguido entre tres modelos de negociación colectiva en el sector público, a través de las cuales se alcanzan diferentes acuerdos con distinto valor y eficacia en cada caso. Estos tres modelos son a) los acuerdos sin valor jurídico; b) los convenios con eficacia jurídica condicionada a un sistema complejo y c) los convenios colectivos válidos de pleno derecho.

${ }^{20}$ PANIZZA DOLABDJIAN, Carolina - "La negociación colectiva en el sector público" en XXVI Jornadas de Derecho del Trabajo y la Seguridad Social, cit., pág. 225 y ss.

${ }^{21}$ IGARZA FUNES, Gustavo Pablo "Negociación Colectiva en el Sector Público Estatal" en Revista de la Universidad de Montevideo, Número 33, Año XVII (2018), pág. 206.

${ }^{22}$ BAJAC, Laura - "La negociación colectiva en el sector público" en Revista Transformación, Estado y Democracia $\mathrm{N}^{\circ} 35$, cit. pág. 38.

${ }^{23}$ RACCIATTI, Octavio, - "Los efectos jurídicos de los Convenios Colectivos en la Administración Pública" en "7 Estudios de Derecho Colectivo del Trabajo", Cuadernos Facultad de Derecho, F.C.U., 1994 pág. 62 a 66. Ver también: GARMENDIA ARIGON, Mario - "La construcción de la teoría sobre el convenio colectivo", en "Estudios jurídicos en homenaje al Prof. Juan Pablo Cajarville Peluffo, F.C.U., Montevideo, 2011, pág. 1147 y sigtes. 
En primer lugar, se encuentra el modelo de negociación colectiva pública a través del cual se alcanzaban acuerdos sin valor jurídico. En estos casos, se admitía la negociación y hasta podían asumirse compromisos de carácter político, pero en ningún caso, se asumían obligaciones jurídicas derivadas de un convenio.

En segundo lugar, encontramos el modelo de negociación colectiva pública a través del cual se alcanzan convenios con eficacia jurídica condicionada a un sistema complejo. Respecto de este tipo de convenios, se ha señalado que: "En este modelo el convenio tiene sí valor jurídico, pero es únicamente una parte de un proceso complejo en el cual primero se celebra el acuerdo, el cual queda supeditado a la aprobación del órgano competente para que tenga valor jurídico. El ejemplo más común es que lo pactado en el convenio colectivo sea reflejado en el Presupuesto del organismo correspondiente. Esta diferencia fundamental con lo que sucede en la actividad privada se cimienta en razón del interés público que justifica la actividad estatal" ${ }^{24}$.

En tercer lugar, la negociación puede culminar con convenios colectivos válidos de pleno derecho. En estos casos, se alcanza un acuerdo plenamente válido y eficaz, que comienza a desplegar sus efectos desde el momento de su suscripción o desde el momento en que las partes acuerden de entrada en vigencia.

A nuestro criterio, nuestra Ley $\mathrm{N}^{\circ} 18.508$ tiene como objetivo implementar el segundo y tercer modelo de negociación a los efectos de superar dicha primera etapa de la negociación colectiva, que se reducía al alcance de acuerdos políticos sin ningún tipo de valor jurídico. En efecto, creemos que la aprobación de una ley específica para la negociación colectiva en el sector público da reconocimiento expreso al derecho a la negociación colectiva con el Estado y otorga un marco específico, para que se puedan alcanzar convenios vinculantes entre las partes y generadores de derechos y obligaciones de carácter jurídico. Esta, es la única interpretación plausible con el dictado de la ley, ya que, para poder realizar acuerdos políticos entre las organizaciones de funcionarios y los organismos estatales, no se requería ley alguna.

Asimismo, la superación del primer nivel de negociación no implica que la migración hacia los otros modelos no permita contemplar las particularidades de la negociación colectiva con el Estado. En efecto, el segundo modelo de negociación contempla expresamente que cierta materia, pueda estar reservada o bien a la constitución o bien a la ley ${ }^{25}$.

Sin perjuicio de ello, debe tenerse claro que, tanto en el segundo como en el tercer modelo, se suscribe un convenio colectivo plenamente válido que genera obligaciones para ambas partes. Lo que varía en uno y otro caso es la eficacia del mismo, la cual, si la organización estatal así lo previene, podrá quedar condicionada a la aprobación de los restantes integrantes del sistema. No obstante, la obligación de la Administración de realizar sus máximos esfuerzos para que se cumpla la condición no se ve suspendida en su eficacia y está plenamente vigente desde el monto en que se suscribe el convenio. Por lo que, tal como veremos más adelante, si el Estado no realiza sus mayores esfuerzos para que se cumpla la condición y el Convenio devenga plenamente eficaz, incurrirá en responsabilidad.

${ }^{24}$ IGARZA FUNES, Gustavo Pablo “Negociación Colectiva en el Sector Público Estatal” en Revista de la Universidad de Montevideo, Número 33, Año XVII (2018), pág. 184.

${ }^{25}$ Ob. Cit. pág. 212. 


\section{NATURALEZA JURÍDICA DEL CONVENIO COLECTIVO PÚBLICO}

Como ya se señalara anteriormente, la Ley $\mathrm{N}^{\circ} 18.508$ ha superado el modelo de negociación colectiva tendiente a obtener acuerdos políticos, adoptando como modelos aquellos tendientes a obtener como resultado convenios colectivos en el sentido estricto del concepto.

$\mathrm{Al}$ respecto, nuestra doctrina ha definido a los convenios colectivos como aquellos "acuerdos celebrados entre un empleador, un grupo de empleadores o una entidad gremial de empleadores con un grupo o sindicato de trabajadores para fijar las condiciones a las que deben ajustarse los contratos individuales de trabajo" 26 .

Pues bien, respecto al convenio colectivo arribado en el sector público, mucho se ha discutido acerca de si el mismo tiene naturaleza jurídica contractual o normativa (tesis contractualista y normativa respectivamente). Asimismo, también se ha postulado una posición ecléctica conforme con la cual, el convenio colectivo sería «un híbrido con cuerpo de contrato y alma de ley» ${ }^{27}$.

Asimismo, respecto de los que postulan la tesis contractualista, también se ha analizado si se trata de un contrato de derecho público o privado, llegándose a la conclusión de que "se trata de contratos norma de derecho público, toda vez que: a) se refieren al mejoramiento de las condiciones de trabajo en la administración pública; b) tienden a asegurar el funcionamiento y la continuidad de la función pública; c) complementan la normativa que regula la relación funcional, en cuanto a la materia encartado en el art. 65, inc. 1, de la Constitución" ${ }^{28}$.

No obstante, más allá de la tesis que se adopte, lo que ya nadie discute es que el convenio colectivo es fuente de Derecho y que, como tal, es creador de una regla de derecho que resulta vinculante para las partes e incluso, para los terceros. Al respecto, se ha señalado que: "La autonomía de la voluntad colectiva implica, nada más y nada menos, la posibilidad de que los sujetos colectivos creen normas jurídicas y de aquí la relación con la autonomía del derecho público. El Estado ya no delega únicamente en organizaciones públicas autónomos como los municipios o entes, la posibilidad de crear normas, sino que, a través de la negociación colectiva, son los sujetos colectivos a quienes delega o a quienes se les reconoce, la potestad de crear normas jurídicas. Sin dudas, estamos ante una nueva fuente de derecho, que quebró el monopolio estatal en la creación de las normas jurídicas" ${ }^{29}$.

En el mismo sentido, se ha pronunciado la jurisprudencia a través de las sentencias del Tribunal de Apelaciones en lo Civil de Primer Turno $N^{\circ} 140$ de 31 de mayo de 2006 y de la Suprema Corte de Justicia N 932 de 19 de diciembre de 2008, que, con matices,

${ }^{26}$ PLA RODRIGUEZ, Américo - "La definición de los convenios colectivos”, en A.A.V.V. - «Veintitrés estudios sobre convenios colectivos», F.C.U., Montevideo, 1988, pág. 10 y sigtes.

${ }^{27}$ DELPIAZZO, Carlos E. "Derecho Administrativo General", cit., Tomo I, Segunda Edición Actualizada y Ampliada, pág. 195 y 196.

28 BISACO, Emilio - "Los Convenios Colectivos en la Administración Pública”, en Contratación Administrativa, F.C.U. Montevideo, 1989, pág. 158 y ss.

${ }^{29}$ BAJAC, Laura - "La negociación colectiva en el sector público" en XV Congreso Internacional del CLAD sobre la Reforma del Estado y de la Administración Pública, Santo Domingo, República Dominicana, 2010 . 
reconocieron que los convenios colectivos celebrados por la Administración no pueden ser desaplicados unilateralmente por ésta ${ }^{30}$.

En consecuencia, más allá de cuál sea la tesis que se adopte en cuanto a la naturaleza jurídica de los convenios colectivos alcanzados en el sector público, lo que sí está claro es que los mismos son fuente de Derecho y que, como tales, crean reglas de Derecho vinculantes para ambas partes cuyo incumplimiento puede ser susceptible de causar responsabilidad.

\section{RESPONSABILIDAD DEL ESTADO EN LA NEGOCIACIÓN COLECTIVA}

La responsabilidad del Estado en la negociación colectiva no se reduce a la responsabilidad contractual derivada de incumplir un convenio colectivo plenamente válido y eficaz. Por el contrario, las particularidades de este tipo de negociación pueden determinar el nacimiento de responsabilidad precontractual.

Asimismo, sostendremos en este trabajo la aplicación a la negociación colectiva del art. 1420 del Código Civil y su régimen de verificación ficta de la condición suspensiva. De esta manera si la Administración imposibilita el cumplimiento de la condición necesaria para que el convenio surta efecto (ej. aprobación del presupuesto), el mismo deberá considerarse eficaz, y, por tanto, surgirán las obligaciones que se encontraban condicionadas en su eficacia. En este escenario, si el ente estatal las incumple no concediendo los beneficios pactados, incurrirá en responsabilidad contractual por incumplimiento.

\subsection{Responsabilidad contractual del Estado por incumplimiento del convenio colectivo (art. 1342 del C.C.)}

En nuestro Derecho, la responsabilidad contractual: "comprende todas las hipótesis en que media violación de una obligación preexistente, quedando circunscripta la responsabilidad aquiliana a los casos en que existe violación de un deber jurídico fuera de toda relación obligacional entre los sujetos de la responsabilidad. ${ }^{31}$ ".

En efecto, en nuestro ordenamiento, la responsabilidad contractual no se limita a aquella derivada del incumplimiento de una obligación contractual, sino que alcanza también al incumplimiento de otras obligaciones que no tienen origen convencional (ej. obligaciones impuestas por la ley o por los cuasicontratos) $)^{32}$.

En consecuencia, a los efectos del nacimiento de la responsabilidad contractual, resulta indiferente si el convenio colectivo es un contrato o una norma jurídica. Ello es así en tanto, sea cual sea la tesis que se adopte, lo que está claro es que, para todas las partes, el convenio colectivo configura una regla de derecho generadora de obligaciones preexistentes.

En efecto, la parte que incumpla un convenio colectivo no estará violentando un deber "fuera de toda relación obligacional" sino que, por el contrario, estará violando una

${ }^{30}$ IGARZA FUNES, Gustavo Pablo- "Negociación Colectiva en el Sector Público Estatal" en Revista de la Universidad de Montevideo, Número 33, Año XVII (2018), pág. 211.

${ }^{31}$ GAMARRA, Jorge - "Tratado de Derecho Civil Uruguayo", F.C.U, Montevideo, ,1988, Tomo XX, pág. 46 y ss.

${ }^{32}$ GAMARRA, Jorge - "Tratado de Derecho Civil Uruguayo", F.C.U, Montevideo, ,1988, Tomo XI, pág. 59 a 63 y ss. 
obligación emanada del acuerdo de voluntades que supone la celebración de un convenio colectivo.

Es por ello, que en caso de que el Estado o las organizaciones de funcionarios incumplan dicho convenio colectivo, estarán incurriendo en responsabilidad contractual frente a la otra parte.

Al respecto, vale decir que el incumplimiento "se configura en todos aquellos casos en que el deudor no realiza la prestación en la forma debida; no es otra cosa que la inobservancia del comportamiento debido". ${ }^{33}$ Asimismo, deberá tenerse especialmente en cuenta si la obligación asumida en el convenio colectivo es de medios o de resultado ${ }^{34}$, en tanto en el primer caso, la Administración podrá exonerarse de responsabilidad probando que actuó en forma diligente y en el segundo de los caso, incurrirá en responsabilidad por el solo hecho de no haber podido cumplir con el resultado prometido.

A nuestro entender, cuando el Estado asume la obligación de realizar un determinado incremento salarial o de presupuestar en un determinado colectivo, asume una obligación de resultado, por lo que no puede exonerarse de responsabilidad inclusive, si demuestra que ha realizado sus mejores esfuerzos para lograrlo. En efecto, la única forma en que podría exonerarse de responsabilidad en estos casos es si demuestra que ha operado una causa extraña (art. 1342 del C.C.).

Al respecto, encontramos como antecedente las sentencias del Tribunal de lo Contencioso Administrativo $\mathrm{N}^{\circ} 491$ y $\mathrm{N}^{\circ} 492$ de 21 de junio de 2006 por las cuales se entendió que la crisis económica del año 2002, había configurado una causa extraña que justificaba la imposibilidad de cumplir con un Convenio Colectivo como el celebrado entre Gobierno Departamental de Montevideo y la organización gremial que nucleaba a sus funcionarios ${ }^{35}$.

Sobre el particular, debe señalarse que no se comparte el criterio esbozado por dicha jurisprudencia en tanto aplica incorrectamente el concepto jurídico de causa extraña. En efecto, debe tenerse en cuenta que nuestro ordenamiento exige que la causa extraña sea imprevisible e irresistible por lo que no cualquier circunstancia podrá operar como eximente de responsabilidad. Asimismo, en las obligaciones dinerarias, se excluye la posibilidad de que se verifique una causa extraña en tanto su cumplimiento siempre es posible ${ }^{36}$.

En función de lo anterior, a nuestro criterio no constituyen causa extraña a modo de ejemplo, ni las dificultades financieras para hacer frente a un convenio, ni el desconocimiento de las condiciones financieras de la Administración por parte de la delegación negociadora, ni la no aprobación por parte de un órgano superior de un acto jurídico que permita cumplir con lo pactado, ni los tiempos insumidos por los procedimientos de aprobación presupuestal.

Al respecto, entendemos que la Administración puede prever sobre qué aspectos puede negociar y sobre cuáles no, y debe estar debidamente informada acerca de la voluntad

${ }^{33}$ GAMARRA, Jorge - "Tratado de Derecho Civil Uruguayo", F.C.U., Montevideo, 1992, Tomo XVII, Vol. 1, 2ª edición, pág. 69.

${ }^{34}$ GAMARRA, Jorge - "Responsabilidad contractual", F.C.U., Montevideo, Tomo II, pág. 354.

${ }_{35}$ DELPIAZZO, Carlos E. - "Derecho Administrativo General" A.M.F., Montevideo, Volumen 1, Segunda Edición Actualizada y Ampliada, pág. 199.

${ }^{36}$ GAMARRA, Jorge - "Responsabilidad Contractual", F.C.U., Montevideo, Tomo II, pág. 119. 
política imperante a la hora de celebrar los acuerdos. Por ello, una vez alcanzados, si la Administración no los cumple, incurrirá en responsabilidad contractual y no podrá invocar como causa extraña, ni las dificultades financieras para hacer frente a dichas obligaciones, ni la no aprobación del presupuesto, ni las dificultades internas de la Administración, ni la reserva legal en ninguna materia.

Asimismo, si se trata de obligaciones cuyo cumplimiento no depende únicamente de la Administración vinculada por el convenio, el Estado debe prevenir dicha circunstancia en el acuerdo y condicionar su eficacia a la obtención de dichos actos jurídicos y si no lo hace, quedará vinculada desde el momento de su suscripción, e incurrirá en incumplimiento por el solo hecho de no haberse verificado la prestación prevista. En este sentido, se ha señalado que: "Cuando se trate de materia reservada a la ley o a la aprobación de órganos superiores, si la norma no se sancionara o la aprobación no sobreviniere, habrá responsabilidad de la Administración actuante, si no se eximió expresamente de tal circunstancia”" ${ }^{37}$.

Finalmente, en cuanto a la legitimación activa para demandar al Estado por el incumplimiento de un convenio colectivo, entendemos que la misma recaerá sobre cada uno de los funcionarios en tanto los convenios colectivos establecen derechos que se incorporan directamente a su vínculo funcional. Asimismo, en cuanto al objeto de la reclamación, la misma consistirá en el cúmulo de prestaciones debidas y no cumplidas más los daños y perjuicios generados por dicho incumplimiento.

\subsection{Responsabilidad contractual del Estado por impedir el cumplimiento de la condición (art. $1420 \mathrm{del} \mathrm{C.C.)}$}

Como ya se señaló anteriormente, hay convenios colectivos públicos cuya eficacia jurídica se encuentra condicionada a la aprobación de un sistema complejo de actos, como puede ser la materia presupuestal o estatutaria. Como se dijera, a nuestro criterio, dichos convenios colectivos son plenamente válidos, solo que su eficacia está supeditada a la verificación una condición suspensiva que puede consistir, por ejemplo, en la aprobación del presupuesto o en la aprobación de un estatuto.

No obstante, entendemos que esta hipótesis únicamente se verifica cuando la Administración expresamente ha previsto esta condición en el Convenio Colectivo. En cambio, cuando no lo ha hecho, estamos frente a un convenio colectivo público plenamente válido y eficaz, que se incumple por la sola falta de cumplimiento de la prestación, no siendo en nuestra opinión causa extraña, a modo de ejemplo, ni la falta de aprobación presupuestal, ni estatutaria.

Ahora bien, en caso de que la Administración haya estipulado la condición y la eficacia del convenio haya quedada supeditada al cumplimiento de la misma, debe prestarse especial interés a la conducta que asume el deudor (en este caso el Estado) respecto al cumplimiento de dicha condición. En efecto, desde que se suscribe el convenio, la Administración que participó en la negociación colectiva tiene la obligación de hacer sus mejores esfuerzos para que se verifique la misma. Esto es, debe hacer todo lo que está a su alcance para que se cumpla dicha condición.

37 BIASCO, Emilio - "Los Convenios Colectivos en la Administración Pública”, en Contratación Administrativa, FC.U., Montevideo, 1989, pág. 158 y ss. 
En este sentido, se ha señalado que: "La pendencia de la condición suspensiva no afecta la validez del negocio, éste es válido, pero la relación jurídica que aquel debe producir no está configurada. Sin embargo, igualmente surge una relación, la cual tiene por contenido conductas compatibles con el efecto final, que se alcanzará con la verificación de la condición. De manera que en el referido estado de la condición suspensiva, si bien no surge la relación obligatoria, igualmente las partes se encuentran mutuamente vinculadas, atadas o ligadas, y comprometidas por derechos y deberes que no son los correspondientes a la situación final, al efecto negocial, sino que consisten, para ambas partes, en que ninguna de ellas debe impedir el cumplimiento de la condición, y el correlativo derecho, en caso contrario, de que se le tenga por cumplida. La tutela preventiva del acreedor condicional se efectiviza por intermedio de los actos conservatorios de su derecho, el que se le atribuye en el art. 1420 C.C." 38 .

En cuanto, al fundamento del artículo 1420 del C.C., se ha entendido que el mismo radica en la obligación de conducirse conforme a la buena fe. Al respecto se ha dicho que: "el sujeto tiene el deber instrumental de cumplir con la conducta tendiente a permitir la verificación de la condición (...), deber que no es más que la concreción de la obligación de conducirse con arreglo a la buena fe durante la pendencia de la condición (arts. 1414 y 1420)"39.

Es por ello, que caso de que uno de los sujetos impida el cumplimiento de esa condición, el art. 1420 de nuestro Código Civil prevé como sanción que la condición se reputará cumplida. Asimismo, se ha entendido que para que se repute cumplida, dicho comportamiento impeditivo no necesariamente debe ser doloso (tener la intención de impedir el cumplimiento de la condición), sino que alcanza con que sea culposo (que la condición no se cumpla por impericia o negligencia del sujeto obligado $)^{40}$.

En el caso de la negociación colectiva en el sector público, la Administración actuaría impidiendo el cumplimiento de la condición si intencional o culposamente no realizara los actos y esfuerzos necesarios tendientes a obtener el cumplimiento de la condición. A modo de ejemplo, configuraría una conducta impeditiva el no defender o no realizar las gestiones políticas suficientes para que el presupuesto contemple los créditos necesarios para cumplir con las obligaciones asumidas.

En estos casos, se aplicaría la sanción prevista en el art. 1420 del C.C., teniéndose por cumplida la condición y, por ende, adquiriendo plena eficacia el convenio colectivo alcanzado. En consecuencia, si el Convenio colectivo deviene plenamente eficaz, entonces los funcionarios podrán exigir el cumplimiento de sus obligaciones y en caso de que el Estado no pueda cumplirlas, incurrirá en responsabilidad frente a los mismos al igual que en la hipótesis del convenio colectivo no condicionado.

En este sentido, se ha sostenido que: "si el sujeto cuyo interés es contrario a la verificación de la condición es quien ilegítimamente impide su realización, lesiona una

${ }^{38}$ CAFARO, Eugenio B. y CARNELLI, Santiago - "Eficacia contractual", F.C.U., Montevideo, 1999, pág. 70 у 71.

${ }^{39}$ GAMARRA, Jorge Luis - "Obligaciones y Cuasicontratos", A.A.V.V., F.C.U., Montevideo, 2009, pág. 217.

${ }^{40}$ BLENGIO, Juan - "El art. 1420 del CC. La ficción de cumplimiento de la condición" en Montevideo, 1986, ADCU, Tomo XVII, pág. 283 y 284. 
expectativa y la parte cuyo interés es de signo opuesto debe reparar el daño causado" y agrega que el mismo no sería otro más que "el importe de la obligación (que surge del negocio cuya eficacia típica se produce al reputarse cumplida la condición). La decisión es dura para quien viola el deber de buena fe y es por ello configurable como una pena"41.

En consecuencia, si la Administración con su conducta impide que se cumpla la condición pactada (ya sea de forma dolosa o culposa) entonces la condición se reputará cumplida y el convenio devendrá plenamente eficaz, siendo por tanto también, plenamente exigibles las obligaciones emanadas del mismo. En función de ello, los funcionarios estarán plenamente legitimados activamente para reclamar la totalidad de las obligaciones asumidas por la Administración, no siendo posible obviamente, que la organización estatal invoque como causa extraña la no verificación de la condición.

\subsection{Responsabilidad precontractual del Estado}

Fuera de los casos en que se arriba a un convenio colectivo de carácter público, también existen otras hipótesis en las que el Estado puede incurrir en responsabilidad civil por su conducta en el marco de una negociación colectiva en la etapa precontractual.

Entendemos que ello sucede cuando el Estado violenta su obligación de negociar de buena fe establecido en el art. 5 de la Ley $\mathrm{N}^{\circ} 18.508$, y a modo de ejemplo, no informa debidamente sobre el alcance de su representación (art. 2075 del C.C.), acude a negociar con funcionarios que no están debidamente instruidos o carecen de idoneidad técnica y de representatividad para poder llevar adelante la negociación o inclusive, cuando deliberadamente se incumple con el deber de brindar la información necesaria y comprensible para la negociación en tiempo y forma. En el mismo sentido, se incumple con dicha obligación también cuando se asiste a las negociaciones en forma meramente nominal pero no se cuenta con una verdadera voluntad de negociar.

Al respecto, se ha señalado que: "Actualmente, existe acuerdo en doctrina en que este tipo de responsabilidad tiene lugar por la violación de la obligación de comportarse de buena fe en el período que va desde el comienzo de las tratativas hasta el momento de perfeccionamiento del contrato" 42 .

Asimismo, dicha obligación de comportarse de buena fe adquiere especial relevancia respecto del deber de informar. Ello es así en tanto, en el caso de la negociación colectiva en el sector público, no cabe duda alguna de que la Administración está en poder de información que las organizaciones de funcionarios no poseen, por lo que estos se encuentran en una condición de debilidad frente al Estado. Asimismo, resulta también claro que la información en posesión de la Administración (ej. disponibilidad financiera del Estado) es esencial para poder arribar a una negociación en uno u otro sentido. En efecto, el margen de negociación, como en cualquier negociación colectiva, estará dado por las posibilidades económicas del empleador. Por ello, si la organización estatal no informa debidamente, a nuestro criterio incumple su obligación de actuar de buena fe.

${ }^{41}$ BLENGIO, Juan- "El art. 1420 del CC. La ficción de cumplimiento de la condición" cit., pág. 282.

${ }^{42}$ MANTERO MAURI, Elías - "Perfeccionamiento y Responsabilidad Civil en los contratos con la Administración”, A.M.F., Montevideo, 2011, pág. 35 y 36. 
En este sentido, se ha señalado que: "El suministro de todos los datos y circunstancias que influyen en la contratación, permite tomar una decisión más libre y fundada a los sujetos que van a estipular una relación negocial, por lo que existe unanimidad de opiniones en cuanto a que el cumplimiento del deber de información asegura la libertad de contratación y la justicia de la misma, ubicando al contratante menos ilustrado en paridad de condiciones" ${ }^{\prime 3}$.

Por dicha razón, la consecuencia de haber violentado el deber de obrar de buena fe en la etapa precontractual no puede ser otro más que el nacimiento de la obligación de indemnizar. Y ello es así en tanto: "en todos aquellos casos en que la Administración no honre la obligación de comportarse de buena fe antes del perfeccionamiento del contrato, generará responsabilidad precontractual a su respecto y deberá indemnizar los perjuicios que con tal accionar ocasione" 44 .

En estos casos en que no se cumplió en forma con el deber de informar, el daño puede consistir en "haber estipulado un negocio en distintas condiciones a las que hubiera aceptado, de conocer el verdadero estado de las cosas. El contrato es válido, pero "inadecuado" para satisfacer la necesidad que determinó al sujeto a concluirlo; se trata de adecuar la situación, a la que habría existido de no mediar el comportamiento ilícito de la otra parte" 45 .

En dichos casos, la responsabilidad es de carácter precontractual en la medida que, al momento de verificarse, aún no se ha celebrado el convenio colectivo, y dará derecho a la indemnización por la diferencia entre lo que se acordó y lo que se podría haber acordado, de estar en conocimiento de la información omitida.

En consonancia con ello se ha señalado que: "No hay duda sobre la procedencia de la reparación del daño; la buena fe es fuente de obligaciones contractuales que dan lugar a incumplimiento y resarcimiento del perjuicio causado, resolución del contrato o su mantenimiento". Asimismo, en cuanto a la procedencia de esta responsabilidad en etapa precontractual también se ha dicho que: "hemos examinado la cuestión de las llamadas "inferioridades", que se sitúa en la etapa de perfeccionamiento, en caso de presentarse anomalías de un contratante no previstas por la ley (de las que abusa o explota la otra parte); en este caso, según una doctrina, el límite a la buena fe podría afectar la autonomía privada. Además, para quienes admiten una función "correctiva", también estaríamos ante una limitación a la libertad contractual, en consonancia con la tendencia que reclama "más heteronomía que autonomía" en la formación del contrato"46.

Asimismo, también se configurará responsabilidad precontractual frente a los funcionarios o incluso frente a la organización de funcionarios, cuando se haya acudido a la negociación colectiva sin las facultades suficientes para negociar y también en aquellos casos, en que se cumpla con la formalidad de acudir a las diferentes instancias, pero sin una

${ }^{43}$ GAMARRA, Jorge - "Tratado de Derecho Civil Uruguayo", F.C.U., Montevideo, Tomo XI, Vol. 4, $4^{\mathrm{a}}$ edición, 2006, pág. 121.

${ }^{44}$ MANTERO MAURI, Elías - "Perfeccionamiento y Responsabilidad Civil en los contratos con la Administración", cit., pág. 42.

${ }^{45}$ GAMARRA, Jorge - "Tratado de Derecho Civil Uruguayo", F.C.U., Montevideo, Tomo XI, Vol. 4, cit., pág. 138.

${ }^{46}$ GAMARRA, Jorge - "Buena fe contractual”, F.C.U., Montevideo, 2011, pág. 177 y 182. 
verdadera intención de negociar. En esos casos, lo que deberá indemnizarse son los gastos, los honorarios en que se haya incurrido para poder negociar, así como todo otro daño derivado de dicha situación.

\section{CONCLUSIONES}

De lo analizado precedentemente, puede arribarse a las siguientes conclusiones acerca de la responsabilidad estatal en el marco de la negociación colectiva en el sector público:

a) más allá de cuál sea la tesis que se adopte en cuanto a la naturaleza jurídica de los convenios colectivos alcanzados en el sector público (tesis contractualista, normativista o dualista), lo que sí está claro es que los mismos son fuente de Derecho y que como tales, crean reglas de Derecho vinculantes para ambas partes cuyo incumplimiento puede ser susceptible de causar responsabilidad;

b) cuando el Estado asume la obligación de realizar un determinado incremento salarial o de presupuestar a un determinado colectivo, asume una obligación de resultado, cuyo incumplimiento aparejará responsabilidad contractual frente a los funcionarios y de la cual no puede exonerarse, aunque demuestre que ha obrado en forma diligente;

c) a nuestro criterio no constituyen causa extraña que exima de responsabilidad contractual al Estado, a modo de ejemplo, ni las dificultades financieras coyunturales para afrontar las obligaciones asumidas, ni el desconocimiento de dificultades financieras de la Administración por parte de la delegación negociadora, ni tampoco la no aprobación por parte de un órgano superior de un acto jurídico que permita cumplir con lo pactado;

d) el convenio colectivo que requiera de aprobación o dictado de un acto posterior, es plenamente válido y únicamente quedará suspendido en sus efectos si la Administración expresamente prevé dicha condición en el acuerdo;

e) si la Administración condiciona la eficacia del convenio al cumplimiento de una condición, ésta tiene el deber de realizar sus mejores esfuerzos para el cumplimiento de la misma y si con su comportamiento activo u omiso, intencional o culposo, impide el cumplimiento de esa condición, la misma debe tenerse por cumplida conforme lo establece el art. 1420 de nuestro Código Civil, y en consecuencia, el Convenio Colectivo adquirirá plena eficacia;

f) si el convenio deviene plenamente eficaz en virtud de la sanción impuesta por el art. 1420 , las obligaciones allí previstas devienen exigibles para los funcionarios y la Administración deberá cumplirlas o responder por responsabilidad contractual frente a los funcionarios por el monto total de las mismas.

g) el Estado incurre en responsabilidad precontractual cuando violenta el deber de negociar de buena fe establecido en el art. 5 de la Ley $\mathrm{N}^{\circ} 18.508$, y a modo de ejemplo, no informa debidamente sobre el alcance de su representación (art. 2075 del C.C.), acude a negociar con funcionarios que no están debidamente instruidos o carecen de idoneidad técnica y de representatividad para poder llevar adelante la negociación o inclusive, cuando deliberadamente se incumple con el deber de brindar la información necesaria para la negociación en tiempo y forma. En el mismo sentido, se incumple con dicha obligación también cuando se asiste a las negociaciones en forma meramente nominal pero no se cuenta con una verdadera voluntad de negociar. 


\section{BIBLIOGRAFÍA CONSULTADA}

BAJAC, Laura - "La negociación colectiva en el sector público" en Revista Transformación, Estado y Democracia $\mathrm{N}^{\circ} 35$, pág. 37 y 38.

BAJAC, Laura - "La negociación colectiva en el sector público" en XV Congreso Internacional del CLAD sobre la Reforma del Estado y de la Administración Pública, Santo Domingo, República Dominicana, 2010.

BISACO, Emilio - "Los Convenios Colectivos en la Administración Pública", en Contratación Administrativa, F.C.U. Montevideo, 1989, pág. 158 y ss.

BLENGIO, Juan - "El principio de equilibrio con especial referencia a su incidencia en la ecuación contractual en la emergencia económica. Primera Parte” F.C.U., Montevideo, 2005, ADCU, Tomo XXXV, pág. 590.

BLENGIO, Juan- "El art. 1420 del CC. La ficción de cumplimiento de la condición" en F.C.U. Montevideo, 1986, ADCU, Tomo XVII, pág. 283 y 284.

CAFARO, Eugenio B. y CARNELLI, Santiago - "Eficacia contractual”, F.C.U., Montevideo, 1999, pág. 70 y 71.

CAGNONI, José Aníbal - "Evolución del Régimen Jurídico de las personas públicas no estatales" en Revista de Derecho Público, F.C.U., Montevideo, 1992, № 1, pág. 27 y ss.

CAJARVILLE, Juan Pablo - "Sobre Derecho Administrativo", F.C.U., Montevideo, 2009, Tomo I, pág. 719 y ss.

CORREA FREITAS, Rubén y VÁZQUEZ, Cristina en "Manual sobre la función pública", F.C.U., Montevideo, 1998, pág. 35 y 36.

DELPIAZZO, Carlos E. - "Derecho Administrativo Especial", AMF, Montevideo, 2015, Volumen 1, Tercera Edición Ampliada y Actualizada, pág. 201.

DELPIAZZO, Carlos. E - "Derecho Administrativo General” A.M.F., Montevideo, 2015, Volumen 1, Segunda Edición Actualizada y Ampliada, pág. 199.

DURAN, Beatriz y SANTESTEVAN, Ana - "Ley N 18.508 en el sector público" en "Cuarenta Estudios sobre la Nueva Legislación Laboral Uruguaya”, F.C.U., Montevideo, 2010, pág. 74 y ss.

GAMARRA, Jorge - “Tratado de Derecho Civil Uruguayo”, F.C.U., Montevideo, 2006, Tomo XI, Vol. 4, 4a edición, pág. 121.

GAMARRA, Jorge - "Buena fe contractual”, F.C.U., Montevideo, 2011, pág. 177 y 182.

GAMARRA, Jorge - "Responsabilidad contractual”, F.C.U., Montevideo, Tomo II, pág. 354.

GAMARRA, Jorge - “Tratado de Derecho Civil Uruguayo”, F.C.U, Montevideo, 1988, Tomo XX, pág. 46 y ss.

GAMARRA, Jorge - “Tratado de Derecho Civil Uruguayo”, F.C.U, Montevideo,1988, Tomo XI, pág. 59 a 63 y ss.

GAMARRA, Jorge - “Tratado de Derecho Civil Uruguayo”, F.C.U., Montevideo, 1992, Tomo XVII, Vol. 1, $2^{\text {a }}$ edición, pág. 69.

GAMARRA, Jorge - "Vigencia actual del principio de buena fe" en F.C.U. , Montevideo, 1977, ADCU, Tomo VII, pág. 92

GAMARRA, Jorge Luis en "Obligaciones y Cuasicontratos”, A.A.V.V., F.C.U., Montevideo, 2009, pág. 217.

GARMENDIA ARIGON, Mario - "La construcción de la teoría sobre el convenio colectivo", en "Estudios jurídicos en homenaje al Prof. Juan Pablo Cajarville Peluffo, F.C.U., Montevideo, 2011, pág. 1147 y sigtes.

IGARZA FUNES, Gustavo Pablo "Negociación Colectiva en el Sector Público Estatal" en Revista de la Universidad de Montevideo, Número 33, Año XVII (2018), pág. 206.

LABORDE GOÑI, Marcelo - "El principio de buena fe como rector del Ejercicio de la Función Pública” en Revista de Derecho Público, F.C.U., Montevideo, 2016, Año 25, Número 50, diciembre de 2016, pág. 67 
LÓPEZ MESA, Marcelo y ROGEL VIDE, Carlos - "La doctrina de los actos propios" editorial Reus y BdeF, 2005, pág. 64.

MANTERO MAURI, Elías - "Perfeccionamiento y Responsabilidad Civil en los contratos con la Administración”, A.M.F., Montevideo, 2011, pág. 35 a 42.

PANIZZA DOLABDJIAN, Carolina - "La negociación colectiva en el sector público" en XXVI Jornadas de Derecho del Trabajo y la Seguridad Social, F.C.U., Montevideo, 2015, pág. 225 y ss.

PLA RODRIGUEZ, Américo - "La definición de los convenios colectivos”, en A.A.V.V. - «Veintitrés estudios sobre convenios colectivos», F.C.U., Montevideo, 1988, pág. 10 y sigtes.

PRAT, Julio - "Derecho Administrativo", Montevideo, 1978, Tomo III, volumen I, pág. 29.

RACCIATTI, Octavio - "Los efectos jurídicos de los Convenios Colectivos en la Administración Pública" en "7 Estudios de Derecho Colectivo del Trabajo" en F.C.U, Montevideo, 1994, Cuadernos Facultad de Derecho, pág. 62 a 66.

RACCIATTI, Octavio, GARMENDIA, Mario, GOLDFLUS, Sandra - "Relaciones industriales, incluyendo disputas colectivas en el sector público." en Revisa de Derecho Laboral, Tomo XLIII, ํ1ㅗ. Julio-Setiembre 2000, Montevideo, 2000, pág. 577.

SAYAGUÉS LASO, Enrique - "Criterio de distinción entre las personas jurídicas públicas y privadas", Revista de Derecho Público y Privado, Año VII, N 83, pág. 259 y ss.

SAYAGUÉS LASO, Enrique - "Tratado de Derecho Administrativo", Montevideo, 1974, Tomo I, pág. 263.

SCHIAVI, Pablo - “¿Convenios colectivos de la Administración son fuente de derecho administrativo? En Revista de Derecho Administrativo Económico, Pontificia Universidad Católica de Chile, Número 29, Año. 2019.

VELOSO, Natalia - "Sociedades de Economía Mixta", A.M.F., Montevideo, 2012, pág. 56.

Fecha de recepción: 24 setiembre 2019.

Fecha de aceptación: 22 octubre 2019. 